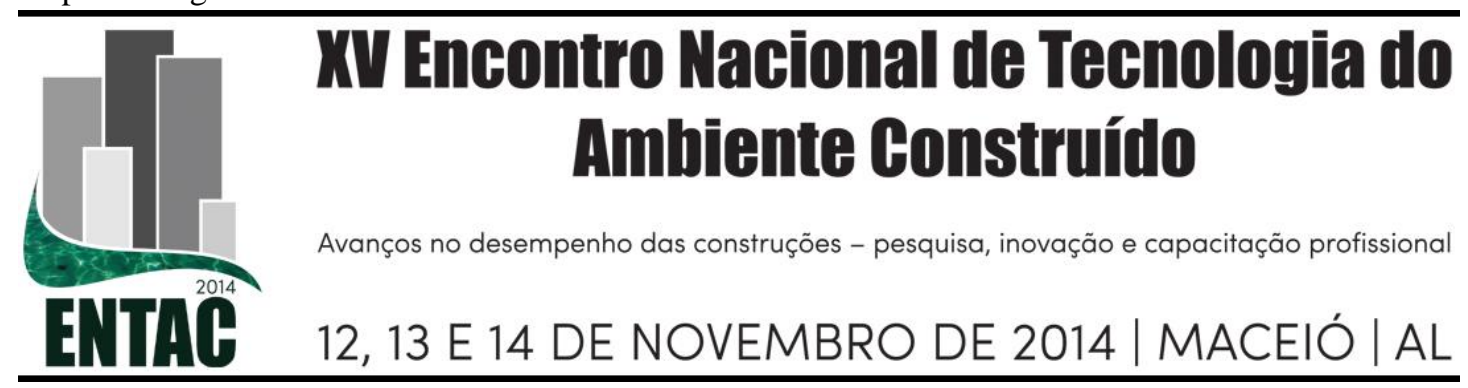

\title{
PERGUNTAS IRRESPONDÍVEIS NO CONTEXTO DA CONSTRUÇÃO CIVIL
}

\author{
CÂNDIDO, Luis Felipe (1); HEINECK, Luiz Fernando Mählmann
}

(1) PEC/UFC, e-mail: luisf_civil@yahoo.com.br, (2) UECE, e-mail: freitas8@terra.com.br

\begin{abstract}
RESUMO
Este trabalho tem por objetivo apresentar uma bateria de perguntas que testam o grau de conhecimento e prática de ações ligadas à construção enxuta por parte de supervisores de obras e coordenadores de projetos, na figura tanto de engenheiros de obra como arquitetos. Estas perguntas compõem o questionário de Perguntas Irrespondíveis no Contexto da Construção Civil, um dos questionários da série desenvolvida pela UFSC. Procura-se, também, identificar aquelas áreas da produção enxuta que os profissionais têm domínio a partir de sua experiência ou da assimilação de conceitos em cursos específicos como aqueles propiciados por disciplinas de um curso de especialização em gerenciamento de obras. Um grupo de 35 alunos responderam as 100 questões formuladas proporcionando a visualização dos resultados práticos dessa ferramenta os quais foram apresentados conforme a classificação sugerida por Amaral et al (2007) que sugere que a construção enxuta deve se preocupar com questões relativas aos Ciclos, ao Fluxo, a Coordenação de atividades, a Qualidade de Vida no Trabalho e a prática do Kaizen. Pode-se concluir que as principais dificuldades dos respondentes estão ligadas a dois elementos essenciais da produção enxuta, que são a Organização do Fluxo de Atividades e Estações de Trabalho e Melhoria Contínua (Kaizen).
\end{abstract}

Palavras-chave: Ensino na construção, construção enxuta, ferramentas de ensino

\begin{abstract}
This paper aims to present a series of inquires that assess the level of knowledge and practices regarding the Lean Construction by supervisors and project coordinators construction like architects and construction site engineers. These questions belong to the Unanswerable Questions in the Context of Building Construction (simply called of Uquest) one of the questionnaires of a series developed by UFSC researchers to transmit Lean Construction knowledge. Is intended also, to identify the areas of Lean production which the professionals has domain from their experience or concepts assimilationby specific disciplines of post-graduation courses in Construction Management. A group of 35 experienced professionals answered the 100 formulated questions providing the practice results of the tool used: Uquest. These results were presented according to classification suggested by Amaral el al (2007). In this classification, the main concepts of Lean Construction were arranged in 5 pillars: Cycle, Flow, Coordination of activities, Safety and Quality in construction site and Kaizen Practice. As conclusion, the main barriers to Lean concepts comprehension by the respondents were related to two essential elements of Lean Production: (1) organizing the flow of activities and workstations and (2) continuous improvement (Kaizen)
\end{abstract}

Keywords: Teaching in construction, lean construction, skills for teaching

\section{INTRODUÇÃ̃O}

A construção enxuta trouxe novos conceitos de produção para construção civil e criou um novo paradigma na escolha dos processos gerenciais das empresas. $O$ reconhecimento do fluxo do processo como parte gerenciável em detrimento da visão da 
conversão implicou uma mudança drástica na nova forma de gerenciamento dos processos de produção (KOSKELA, 1992).

O trabalho parte do pressuposto que o conhecimento a despeito desta nova filosofia de produção existe e está sedimentado aguardando sua contínua aplicação, ou seja, verifica-se ainda um descompasso entre assimilação conceitual e a efetiva prática, estando aberto a experimentações que busquem analisar esse binário: filosofia x prática.

Neste contexto, pesquisadores da Universidade Federal de Santa Catarina (UFSC) desenvolveram uma série de questionários como ferramentas de avaliação do conhecimento no ensino da construção enxuta em cursos de formação (graduação e pósgraduações). Estes questionários foram divididos em: 1) Comportamento Enxuto; 2) Comportamento Normal; 3) Perguntas Irrespondíveis no Contexto da Construção Civil; 4) Inovações Tecnológicas e 4) Variabilidade.

O presente trabalho tem por objetivo, portanto, apresentar os resultados da aplicação de um dos questionários da série da UFSC: Perguntas Irrespondíveis no Contexto da Construção Civil. Como contribuição os autores esperam apresentar a ferramenta citada, proporcionando sua disseminação e analisar o nível de conhecimento lean e suas potenciais lacunas do conhecimento a partir das respostas fornecidas por um grupo de 35 alunos de pós-graduação em gerenciamento da construção.

\section{REFERÊNCIAL TEÓRICO}

O referencial teórico está concentrado em duas grandes áreas. A primeira é aquela que envolve os conceitos básicos de Produção e Construção Enxuta, exemplificados pelos trabalhos de Spear e Bowen (1999), Santos et al (2000,2002), Picchi (2001), Formoso et al (2002) e Fontantini e Picchi (2003). Estes trabalhos podem ser tomados como representativos da hoje vasta bibliografia na área, introduzindo e explorando os conceitos da produção enxuta a partir de seu potencial de aplicação às empresas, notadamente as de construção civil, como a maioria das publicações acima citadas o fazem. Esta área do referencial indica que o conhecimento existe, está sedimentado, aguardando sua continua aplicação e o desenvolvimento de gerentes versados na mesma.

Uma segunda área é aquela formada pelos trabalhos que buscam classificação das filosofias, princípios, técnicas, ações, indicadores e exemplos práticos bem sucedidos envolvidos com este novo paradigma industrial. Com objetivo de resgatar aspectos históricos, Ferro (1990) já no início da década esgotava o elenco de conceitos da produção enxuta através de 15 itens a serem implantados na realidade industrial. As classificações oscilam daí entre 3 grandes áreas sugeridas por Koskela (2000), ações relativas aos quesitos Tarefa, Fluxo e Valor, às 14 características sugeridas por Liker (2007).

Não sendo objetivo deste trabalho teorizar sobre a pertinência destas classificações termina-se adotando aquela proposta por Amaral et al (2007), sugerindo que a construção enxuta deve se preocupar com questões relativas aos Ciclos, ao Fluxo, a Coordenação das atividades, a Qualidade de Vida no Trabalho e a prática do Kaizen, classificação esta que passa a ser utilizada no presente trabalho.

Estas classificações tem sido utilizadas para dar um passo a mais, ou seja, inquirir de gerentes e funcionários ligados ao chão de fábrica o seu grau de conhecimento, intuitivo ou aprendido em sala de aula, a respeito da construção enxuta. Esta é a linha de trabalhos de Bressiani et al (2003), Ferrari Filho et al (2004) e Sellitto et al (2004). 
Todos estes trabalhos estabelecem a gradação do conhecimento por parte dos entrevistados entre várias facetas da produção enxuta. É nesta linha de investigação que este trabalho se insere.

No entanto, diferentemente dos demais, a investigação está baseada em questões objetivas, incisivas, detalhadas sobre a realidade operacional do dia a dia das obras. Assim, ao invés do trato com conceitos ou questões genéricas, sujeitas a interpretações e a eventuais mecanismos de autodefesa quanto a respostas, estabelece-se a possibilidade de definições do tipo sim/ não, sabe/ não sabe, tem consciência/ alienação em relação aos quesitos formulados.

Ademais, o método de investigação foi desenhado para ser aplicado a um grupo específico de interlocutores no caso profissionais com interesses na área de gerencia de obras.

\section{METODOLOGIA}

Este artigo foi realizado com base em um questionário aplicado em um curso de especialização voltado para Construção Civil, especificamente no campo de Gerenciamento de Obras. Um grupo de 35 alunos respondeu ao questionário dos quais 17 foram considerados válidos por terem apresentado repostas para grande maioria das 100 questões formuladas. Salienta-se que o questionário foi considerado longo por parte dos respondentes o que fez com que muitos não chegassem ao final da tarefa.

Os alunos avaliados trabalhavam em empresas de qualificação acima da média já que um dos critérios de seleção para ingressar no curso de especialização era a perspectiva futura de aplicação dos conhecimentos ministrados nas disciplinas de pós-graduação.

Os questionários foram aplicados após os alunos concluírem disciplinas específicas da área de construção enxuta. Pressupõe-se, desta forma, que os participantes já estivessem preocupados com a identificação de princípios e ações ligadas a produção enxuta em suas obras.

A ideia é de que somente um conhecimento aprofundado sobre toda a filosofia de Construção Enxuta permitiria um posicionamento afirmativo por parte dos participantes. Do contrário, a falta de conhecimento na área de Construção Enxuta faria com que esses mesmos desconhecessem a natureza das perguntas ou nada tivessem a dizer sobre elas.

As perguntas colocavam os respondentes em cheque quanto ao seu conhecimento de situações já vivenciadas em obra, decisões tomadas e resultados obtidos. Muitas colocavam-se como surpresas aos inquiridos, que não esperariam haver este tipo de preocupação no gerenciamento de obras para melhorar seus resultados. Dois tipos de respostas eram esperados, um posicionamento positivo (contabilizado como sim) ou negativo (contabilizado como não) em relação ao quesito. Solicitava-se que os alunos fizessem um esforço para não cair em respostas evasivas do tipo depende, varia ou são muitas variáveis em jogo.

No caso afirmativo (positivo) tinha-se um posicionamento por parte do respondente que demonstrava ter uma resposta a dar em relação ao quesito, mesmo que não necessariamente alinhada àquilo que a produção enxuta propõe, os quais foram contabilizados como Sim. No caso de resposta negativa se estariam diante de conhecimentos que os respondentes não teriam, não estaria alerta sobre, não se 
preocupariam, ou finalmente, que dariam pouca importância na busca de melhorias gerenciais, os quais foram contabilizados como Não.

Este desconhecimento reforçaria a necessidade de disciplinas mais aprofundadas na área de produção enxuta ou, alternativamente, a prática em obra de seus conceitos avaliando os resultados positivos que delas podem decorrer.

\section{PROPOSTA DE QUESTIONAMENTOS}

Diante do levantamento feito com um questionário contendo 100 perguntas, foram extraídas aquelas consideradas mais relevantes, segundo o critério de quantidade de respostas pertinentes. Estas foram apresentadas no Quadro 1.

\section{Quadro 1 - Proposta de questionamentos}

\begin{tabular}{|c|}
\hline Perguntas Gerais \\
\hline $\begin{array}{l}\text { Cite atributos introduzidos em sua obra, quer no produto quer no processo, que melhoram o valor } \\
\text { percebido pelo cliente (atributos com valor menor que } \mathrm{R} \$ 500,00 \text { ) }\end{array}$ \\
\hline $\begin{array}{l}\text { Que modificações foram realizadas em relação a sua obra anterior que melhoraram o valor } \\
\text { recebido pelo cliente (melhorias com valor inferior a } \mathrm{R} \$ 500,00) \text { ? }\end{array}$ \\
\hline $\begin{array}{l}\text { Quanto tempo leva para abrir o portão da obra, retirar a caçamba de entulho e colocar uma nova } \\
\text { no seu lugar? }\end{array}$ \\
\hline $\begin{array}{l}\text { Qual a duração para realizar o revestimento externo? Em quantos ciclos o revestimento externo } \\
\text { está dividido? Como a fachada foi dividida em termos de comprimento de balança? }\end{array}$ \\
\hline Qual o critério para determinar o comprimento da balança (jaú, andaime)? \\
\hline $\begin{array}{l}\text { Em que circunstâncias a obra funcionou sem dar dor de cabeça, sem estar faltando nada? Quando } \\
\text { foi isso? Quanto tempo durou? Ao que este momento de calmaria pode ser atribuído? }\end{array}$ \\
\hline $\begin{array}{l}\text { Qual é o caminho crítico da obra? Quais as atividades deste caminho crítico? O que foi feito para } \\
\text { acelerar o caminho crítico para não atrasar a entrega da obra? }\end{array}$ \\
\hline O que pode ser feito com antecedência para melhorar o serviço de colocação de forro de gesso? \\
\hline $\begin{array}{l}\text { Que experiências tenho feito ultimamente dentro e fora do trabalho? Tenho medo de } \\
\text { experimentar algo novo? Quais os riscos que vejo em experimentar? }\end{array}$ \\
\hline O que fiz hoje de útil a ponto de achar que alguém deveria me pagar pelo que fiz? \\
\hline $\begin{array}{l}\text { Que problemas de materiais foram detectados pelo almoxarifado ultimamente? Para quem estes } \\
\text { problemas foram reportados? Os problemas foram sanados? }\end{array}$ \\
\hline $\begin{array}{l}\text { Quem determina a prioridade de atendimento pela betoneira? Quem recebe a primeira massa pela } \\
\text { manhã? Até que horas do dia é possível pedir massa? }\end{array}$ \\
\hline $\begin{array}{l}\text { Grande parte dos problemas em obra pode ser evitado planejando-se serviço com alguma } \\
\text { antecedência? O fato de muita coisa mudar em obra, de existirem muitas influências externas no } \\
\text { dia a dia, não impede que seja feito o planejamento para a obra? }\end{array}$ \\
\hline $\begin{array}{l}\text { As atividades da lista reserva estão em condições de serem prontamente executadas? Não falta } \\
\text { nada para dar início a elas? }\end{array}$ \\
\hline $\begin{array}{l}\text { Cite exemplos em que a precedência entre atividades não foi respeitada, obrigando a obra a criar } \\
\text { proteções e mecanismos para permitir esta inversão de sequencia. }\end{array}$ \\
\hline $\begin{array}{l}\text { Consulto permanentemente as previsões meteorológicas para o dia e para a semana de trabalho? } \\
\text { Acredito nas previsões meteorológicas ou acho que elas erram sempre? }\end{array}$ \\
\hline $\begin{array}{l}\text { Ao interagir com terceiros procura-se falar apenas sobre as coisas positivas da obra, ou os } \\
\text { problemas também são reconhecidos? Acredita-se que terceiros possam ser fonte de inspiração } \\
\text { para sanar eventuais dificuldades em obra? }\end{array}$ \\
\hline $\begin{array}{l}\text { O mérito em obra e no escritório é reconhecido em função da contribuição para o fluxo de } \\
\text { trabalho e não pelo relacionamento social das pessoas? O mérito é permanentemente reconhecido } \\
\text { e exaltado? Existem diplomas para reconhecimento do mérito? }\end{array}$ \\
\hline $\begin{array}{l}\text { Existem lugares onde sentar, desenhar e discutir os detalhes da obra ou tudo tem que ser feito em } \\
\text { pé? Existe bastante papel para desenhar e fazer rascunhos em obra? Plantas, desenhos e }\end{array}$ \\
\hline
\end{tabular}




\section{Perguntas Gerais}

especificações são facilmente acessáveis? As informações em obra e no escritório não são escondidas e não fontes de poder?

Quando foi a última vez que admiti que errei ? Quando foi a última vez que disse que gostaria de conhecer mais sobre um assunto ? Em algum momento não tive vergonha de dizer que não sabia, ou que errei ? Como foi isto ?

Que detalhes em obra são padronizados (degraus de escada, corrimãos, floreiras, bancadas de banheiro)?

Porque não cabem 3 jericas na prancha do guincho?

Quanto tempo leva para abrir a cancela do guincho em determinado andar e retirar as jericas do mesmo?

Qual o peso de uma girica cheia? Que volume ela pode transportar?

Onde e como é feita a limpeza de restos de concreto e argamassa presentas nas jericas e carrinhos de mão? Para onde é conduzida está água servida?

Qual a inclinação das rampas para dar acesso ao material, desde o portão da obra até a área de armazenagem ,desta até a betoneira e depois até o guincho ? Em geral a rampa é ascendente para carrinhos carregados? Porque a rampa é descendente (a favor da gravidade) para carrinhos que voltam vazios e ascendentes para os que vão cheios?

Qual o ponto de pedido para a areia, cimento e pregos das várias bitolas? Qual o estoque mínimo para estes materiais?

Quantas atividades de melhoria estão sendo feitas hoje? Quais atividades de kaizen estão previstas para a próxima semana? Quais atividades são de fluxo e quais são kaizen de processo?

Existe caixa de sugestões de melhoria? Quais destas sugestões estão sendo implementadas?

Cite partes ou dispositivos de equipamentos de obra que podem dar problema em obra? Existe $\mathrm{m}$ peças reservas ou substitutas? Em quanto tempo chega o socorro? Qual o telefone e o endereço de pessoas ou lojas que podem providenciar o conserto ou a substituição das partes defeituosas?

Qual a data prevista para entrega dos elevadores em obras? Onde as máquinas e equipamentos dos elevadores serão depositados? Quais os detalhes do poço, casa de máquinas, soleiras e portadas de acesso que já estão padronizados?

Qual o humor dos operários nas várias frentes de trabalho? Quem está triste ou deprimido? Quem está adoentado e mesmo assim trabalhando?

Fonte: dos autores.

Segundo a classificação anteriormente escolhida para este trabalho (AMARAL, 2007), as principais categorias em relação às quais se tem expectativa que os praticantes da produção enxuta tenham um posicionamento positivo foram discriminadas na Tabela 1. Esta tabela apresenta a percentagem de questões referentes a cada uma das áreas considerando o total de 100 questões formuladas.

\section{Tabela 1 - Percentagem de questões formuladas por categoria de conhecimento sobre Construção Enxuta}

\begin{tabular}{ccc}
\hline Nome da Categoria & Código & $\begin{array}{c}\text { \% de } \\
\text { Questões }\end{array}$ \\
\hline Identificação de Valor para o Cliente & $\mathrm{A}$ & $4 \%$ \\
Organização do Trabalho em Ciclos Repetitivos & $\mathrm{B}$ & $9 \%$ \\
Organização do Fluxo de Atividades entre as Estações de Trabalho & $\mathrm{C}$ & $24 \%$ \\
Coordenação e Direção das Operações no Curto Prazo & $\mathrm{D}$ & $31 \%$ \\
Aumento da Qualidade de Vida no Trabalho & $\mathrm{E}$ & $11 \%$ \\
Melhoria Contínua (Kaizen) & $\mathrm{F}$ & $14 \%$ \\
Medição de Desempenho & $\mathrm{G}$ & $2 \%$ \\
Custos de Produção & $\mathrm{H}$ & $5 \%$ \\
\hline
\end{tabular}

Fonte: dos autores. 
Cabe salientar que os itens relativos a Medição de Desempenho e Custos de Produção foram aqui desdobrados a partir do item Melhoria Contínua. Afirma-se que no processo de melhoria há a necessidade de situar-se quanto ao desempenho anterior, para daí provocar ações visando o seu incremento.

\section{RESULTADOS}

Inicialmente, procurou-se detectar dentre as 100 questões formuladas aquelas que receberam maior percentagem de respostas afirmativas (sei) e negativas (não sei). A seguir são apresentadas nas tabelas 2 e 3 as perguntas formuladas que tiveram maior ocorrência de respostas nestas duas categorias.

Tabela 2 - Distribuição percentual das dez perguntas mais positivamente respondidas dentro das áreas de conhecimento da Construção Enxuta

\begin{tabular}{|c|c|c|c|c|c|c|c|c|}
\hline \multirow[t]{2}{*}{ Perguntas com resposta positivas } & \multicolumn{8}{|c|}{$\begin{array}{c}\text { Códigos de categoria do } \\
\text { Conhecimento (Amaral, 2007) }\end{array}$} \\
\hline & $\mathbf{A}$ & B & $\mathbf{C}$ & D & $\mathbf{E}$ & $\mathbf{F}$ & $\mathbf{G}$ & $\mathbf{H}$ \\
\hline $\begin{array}{l}\text { 5. Qual a espessura média do contrapiso? e dos } \\
\text { revestimentos internos? E dos revestimentos externos? }\end{array}$ & & 70 & & & & & & \\
\hline $\begin{array}{l}\text { 23. Qual o número de operários presentes na obra hoje? } \\
\text { Qual é o número máximo previsto? Quando este número } \\
\text { começa a declinar? }\end{array}$ & & & 66 & & & & & \\
\hline $\begin{array}{l}\text { 27. O que tenho lido ultimamente relacionado com a } \\
\text { minha profissão? Como isto afetou meu trabalho? }\end{array}$ & & & & & & 88 & & \\
\hline $\begin{array}{l}\text { 36. Quem se encarrega na obra de separar materiais da } \\
\text { mesma cor, de mesmo tamanho, de mesma procedência } \\
\text { ou tempo de estocagem para facilitar o trabalho na } \\
\text { frente de serviço? }\end{array}$ & & & 86 & & & & & \\
\hline $\begin{array}{l}\text { 39. Desconfio de tudo que me dizem? Utilizo a máxima } \\
\text { de São Tomé, ver pra crer? Seguidamente estou indo pra } \\
\text { ver, ou seja, fazendo inspeções em loco? }\end{array}$ & & & & 75 & & & & \\
\hline $\begin{array}{l}\text { 40. Gosto de ouvir? Solicito que os encarregados pelo } \\
\text { serviço me expliquem o que estão fazendo? Procuro não } \\
\text { impor minha maneira de fazer o serviço? }\end{array}$ & & & & & 88 & & & \\
\hline $\begin{array}{l}\text { 41. Já arregacei as mangas para pegar junto? Ajudei a } \\
\text { executar um serviço ou atividade burocrática, mesmo } \\
\text { que não seja da minha especialidade? }\end{array}$ & & & 89 & & & & & \\
\hline $\begin{array}{l}\text { 43. Gostaria de receber os materiais e ferramentas como } \\
\text { uma mesa cirúrgica, onde o médico trabalha por música } \\
\text { com o instrumentista? Gostaria de receber materiais e } \\
\text { ferramentas sem pedir, sem gritar? }\end{array}$ & & & 88 & & & & & \\
\hline $\begin{array}{l}\text { 46. Gostaria de colocar no papel e ensinar aos outros a } \\
\text { sequencia com que executo meu trabalho? Ou isto é um } \\
\text { segredo que faz parte da minha profissão e no fundo } \\
\text { determina a minha empregabilidade? }\end{array}$ & & & & & & 100 & & \\
\hline $\begin{array}{l}\text { 48. É importante ter uma lista de atividades a serem } \\
\text { feitas que excede um pouco aquilo que sou capaz de } \\
\text { fazer durante a semana? Em caso de folga na execução } \\
\text { dos serviços estou autorizado a executar algum outro } \\
\text { serviço desta lista? }\end{array}$ & & & & 100 & & & & \\
\hline
\end{tabular}


Fonte: dos autores.

Tabela 3 - Distribuição percentual das dez perguntas respondidas mais negativamente dentro das áreas de conhecimento da construção enxuta

\begin{tabular}{|c|c|c|c|c|c|c|c|c|}
\hline \multirow[t]{2}{*}{ Perguntas com resposta positivas } & \multicolumn{8}{|c|}{$\begin{array}{c}\text { Códigos de categoria do } \\
\text { Conhecimento (Amaral, 2007) }\end{array}$} \\
\hline & A & B & C & D & $\mathbf{E}$ & $\mathbf{F}$ & $\mathbf{G}$ & $\mathbf{H}$ \\
\hline $\begin{array}{l}\text { 8. Qual a produtividade global da obra, homem-hora } / \mathrm{m}^{2} \mathrm{de} \\
\text { área de piso? }\end{array}$ & & & & & & & 89 & \\
\hline $\begin{array}{l}\text { 9. Qual a produtividade da obra grossa e da obra fina? Que } \\
\text { percentagem da duração cada uma destas etapas ocupa no } \\
\text { cronograma? }\end{array}$ & & & & & & & 100 & \\
\hline $\begin{array}{l}\text { 13. Qual é a atividade prevista para início das atividades de } \\
\text { colocação do telhado em obra (ou impermeabilização do } \\
\text { terraço)? Qual é a data prevista para liberação do início dos } \\
\text { serviços na área aberta do térreo? }\end{array}$ & & & & 80 & & & & \\
\hline $\begin{array}{l}\text { 16. Cite } 5 \text { modificações em obra ou nos procedimentos } \\
\text { gerenciais que foram fruto de benchmarking realizado com } \\
\text { outras construtoras? }\end{array}$ & & & & & & 100 & & \\
\hline $\begin{array}{l}\text { 17. Cite modificações em obra ou no escritório que foram } \\
\text { motivadas por benchmarking em outros ramos industriais que } \\
\text { não a construção civil. }\end{array}$ & & & & & & 100 & & \\
\hline $\begin{array}{l}\text { 19. Qual o consumo de homem-hora para realizar o } \\
\text { transporte em obra? É mais do que } 4 \text { horas-homem } / \mathrm{m}^{2} \text { ? É } \\
\text { maior do que } 4 \text { homens-hora por tonelada de material? Qual } \\
\text { a proporção dos serventes empregados no transporte? }\end{array}$ & & & 90 & & & & & \\
\hline $\begin{array}{l}\text { 20. Qual a classificação e a percentagem de custo dos } \\
\text { serventes na curva } A B C \text { ? }\end{array}$ & & & & & & & & 82 \\
\hline $\begin{array}{l}\text { 22. Quais as atividades dos diretores, engenheiros e mestres } \\
\text { no treinamento de operários? Qual o número médio de horas } \\
\text { gastas em treinamento por operário, por ano? }\end{array}$ & & & & & & 89 & & \\
\hline $\begin{array}{l}\text { 24. Que informações de problema de fluxo já foram } \\
\text { reportadas pelo guincheiro para a gerência da obra? }\end{array}$ & & & & 80 & & & & \\
\hline $\begin{array}{l}\text { 25. Quanto tempo os eletrodutos ficam depositados em ora } \\
\text { até sua utilização? E os sacos de cimento? Onde estão } \\
\text { depositados as conexões do esgoto do segundo apartamento } \\
\text { da esquerda para a direita do } 5^{\circ} \text { pavimento da obra? }\end{array}$ & & & 80 & & & & & \\
\hline
\end{tabular}

Fonte: dos autores.

A análise mostra que há uma distribuição razoavelmente equitativa entre as diversas áreas com o predomínio das questões relativas à Organização do Fluxo de Atividades (categoria C) entre as Estações de Trabalho e a Melhoria Contínua (categorias F, G e H) tanto no que tange as repostas positivas como negativas.

É bem verdade que as 100 questões formuladas não se distribuem de maneira homogênea entre as áreas, existindo uma percentagem bem maior daquelas relativas à Organização do Fluxo de Atividades entre as Estações de Trabalho (24\% das questões) e Coordenação e Direção das Operações no Curto prazo (31\%) do que aquelas relativas 
à Organização do Trabalho em Ciclos Repetitivos (9\%), Aumento da Qualidade de Vida no Trabalho (11\%) e Melhoria Contínua (14\%).

Desta forma é de se esperar que haja um maior número de posicionamentos enfáticos relativo às questões sobre fluxos, enquanto aparece com surpresa o destaque dado à área de melhoria contínua. Esta última obteve um pequeno número de questões, mas grande incidência de posicionamentos altamente negativos.

Uma segunda análise foi conduzida avaliando-se todas as questões respondidas e não somente aquelas com a maior incidência de respostas afirmativas e negativas. A seguir a Tabela 4 ilustra os resultados obtidos.

Tabela 4 - Total de questões para cada categoria respondidas (positiva e negativa)

\begin{tabular}{ccccccccc}
\hline Categorias & A & B & C & D & E & F & G & H \\
\hline $\mathrm{N}^{\mathbf{o}}$ de questões com predominância de respostas positiva & - & 5 & 5 & 10 & 7 & 4 & - & 1 \\
\hline $\mathrm{N}^{\circ}$ de respostas com equivalência entre positivas e negativas & 1 & 3 & 4 & 4 & - & 2 & - & 4 \\
\hline $\mathrm{N}^{\circ}$ de questões com predominância de respostas negativas & 2 & 1 & 12 & 7 & 1 & 5 & 3 & 2 \\
\hline $\mathrm{N}^{\circ}$ total de questões & 3 & 9 & 21 & 21 & 8 & 11 & 3 & 7 \\
\hline
\end{tabular}

Fonte: dos autores.

Segundo a Tabela 4 os respondentes estão mais seguros nos quesitos relativos Organização do Trabalho em Ciclos Repetitivos (categoria B), Coordenação e Direção das Operações no Curto Prazo (categoria D) e Aumento da Qualidade de Vida no Trabalho (categoria E), com destacada predominância para este último.

Por outro lado existem dificuldades para se posicionar nos itens relativos às categorias $\mathrm{A}, \mathrm{C}$ e $\mathrm{G}$, com destaque para este último (apesar do pequeno número de questões formuladas nessa categoria).

Outra análise seria fundir os itens relativos a $F$ (Melhoria contínua), G (Medição de desempenho) e H (Custos de Produção) numa única categoria. Neste caso de um total de 21 questões relativas a essa macro área foram contabilizadas, dez teriam respostas predominantemente negativas, enquanto que apenas cinco seriam positivas.

Por fim, a Figura 1 apresenta o percentual de questões positivas em relação ao total para cada categoria, considerando a macro área de melhoria contínua como o somatório das questões de F, G e H.

\section{Figura 1 - Distribuição de acertos por categoria de conhecimento}

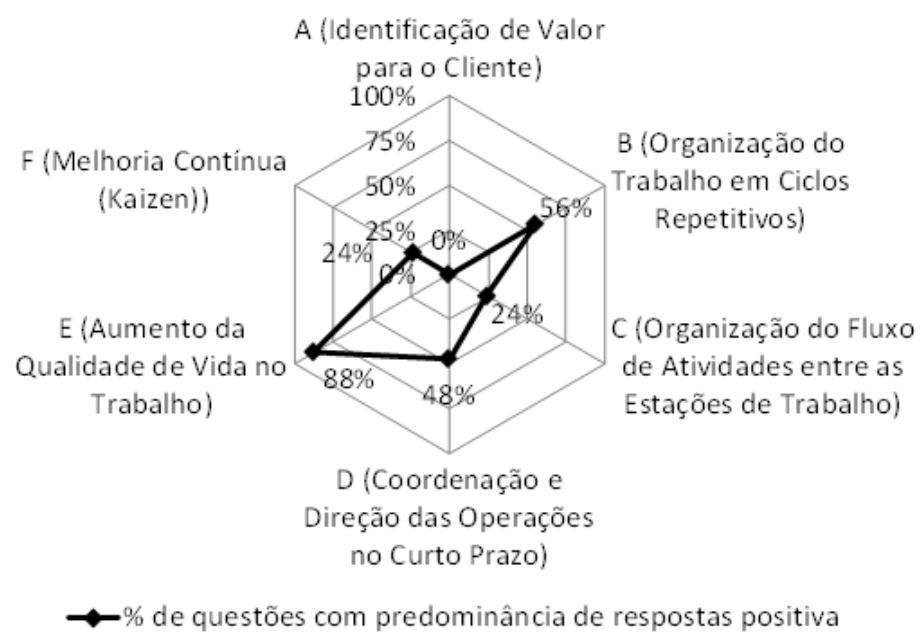

Fonte: dos autores. 
Observa-se, portanto, que ainda assim, as questões sobre melhoria contínua tem baixa incidência em termos de assertividade positiva, assim como Organização do Fluxo de Atividades entre as Estações de Trabalho. Destaca-se ainda, a Identificação de Valor para o Cliente que não obteve pontuações positivas.

\section{CONCLUSÃO}

As dificuldades dos respondentes estão ligadas a dois elementos essenciais da produção enxuta, que são: (C) Organização do Fluxo de Atividades entre as Estações de Trabalho e (F) Melhoria Contínua (Kaizen). De outra parte, nota-se um domínio daquelas que seriam as habilidades básicas dos respondentes como gestores de obras: (B) Organização do Trabalho em Ciclos Repetitivos e a (D) Coordenação e Direção das Operações no Curto Prazo.

É oportuno lembrar que (D) Coordenação e Direção das Operações no Curto Prazo também pode ser confundidas com esforços gerenciais exercidos pelos respondentes na tentativa de contemporizar os inúmeros problemas que ocorrem em obra pela sua falta de organização naquilo que se chama de gestão por apagar incêndios. Desta forma não é surpresa que os participantes dessa pesquisa se sintam capacitados na área de coordenação.

Também não é surpresa a quase hegemônica capacidade de dar respostas afirmativas relativas ao item E (Aumento da Qualidade de Vida no Trabalho). Lima (1997) já alertava em sua tese de doutorado que as novas relações capital-trabalho na construção civil impunham um melhor atendimento as necessidades básicas do trabalhador, o que resultava numa melhoria da qualidade de vida no trabalho principalmente naqueles itens que dependiam unicamente da provisão de melhores bens materiais relativos à alimentação, alojamento, lazer e dignidade no trabalho.

\section{REFERÊNCIAS BIBLIOGRÁFICAS}

AMARAL, T; HEINECK, L. F; VIEIRO, F. T. Situações de ensino/ aprendizagem intermediadas pelos princípios da construção enxuta. In: V Simpósio Brasileiro de Gestão e Economia da Construção. Campinas, SP, Setembro, 2007.

BRESSIANI, L; SANTOS, D. G; SAFFARO, F. A; SOUZA E SILVA, M. F; HEINECK, L. F. O comportamento dos engenheiros de obra em relação aos princípios Lean. III Simpósio Brasileiro de Gestão e Economia da Construção. São Carlos, SP, Setembro, 2003.

FERRO, J. R. Aprendendo com o "Ohnoísmo" (Produção flexível em massa): lições para o Brasil. Revista de Administração de Empresas. São Paulo, SP, 1990.

FILHO, C. A. F; JÚNIOR, J. A. V. A; KLIPPEL, M. A perspectiva do enriquecimento mútuo entre o Sistema Toyota de Produção e os Sistemas SócioTécnicos: o desenvolvimento de práticas semi-autônomas em célula de manufatura com uso de elementos psicanalíticos. XXIV Encontro Nacional de Engenharia de Produção. Florianópolis, SC, Novembro, 2004.

FONTANNINI, P. S. P; PICCHI, F. A. Mentalidade enxuta da cadeia de fornecedores da construção civil - aplicação de macro-mapeamento. III Simpósio Brasileiro de Gestão e Economia da Construção. São Carlos, SP, Setembro, 2003 
FORMOSO, C. T; SANTOS, A; POWELL, J. A. An exploratory study on the applicability of process Transparecy in Construction Sites. Journal of Construction Research. v 3, n 1, 2002.

KOSKELA, L. Application of the new production philosophy to construction. Technical Report 72. Stanford: Center for Integrated Facility Engineering, Set/1992. $81 \mathrm{p}$.

LIMA, L. Qualidade de vida no trabalho na construção civil. Programa de pósgraduação em Engenharia de Produção, UFSC, Tese de Doutorado, 1997.

LIKER, J. K. O modelo Toyota: 14 princípios de gestão do maior fabricante do mundo. Porto Alegre: Bookman, 2007.

PICCHI, F. A. Lean Thinking (Mentalidade Enxuta): avaliação sistemática do potencial de aplicação no setor de construção. II Simpósio Brasileiro de Gestão e Economia da Construção, Fortaleza, 2001

SANTOS, A; FORMOSO, C. T; TOOKEY, F. R. Expanding the Meaning of Standardisation within Construction Processes. The Total Quality Management Magazine. v. 14. n. 1, 2002, p. 25-33.

SANTOS, A; POWELL, J. A; FORMOSO, C. T. Setting Stretch Target for Driving Continuous Improvement in Construction: Analysis of Brazilian and UK Practices. Work Study. v. 49. n. 2, 2000. p 50-58.

SELLITTO, M. A; BORCHARDT, M; PEREIRA, G. M; OLIVEIRA, G. Graus de importância de critérios de desempenho de uma estratégia enxuta aplicada em uma indústria de serviços. XXIV Encontro Nacional de Engenharia de Produção. Florianópolis, SC, Novembro, 2004.

SPEAR, S; BOWEN, H. K. Decoding the DNA of the Toyota production system. Harvard Business Review. v. 77, n. 5, sept/ oct. 1999. pp. 96-106 